\section{Commentary: Severe carotid stenosis and coronary artery bypass graft: The stroke saga continues}

Phillip G. Rowse, MD, and Pouya Hemmati, MD

Perioperative stroke following coronary artery bypass graft (CABG) surgery is a devastating complication that is associated with increased morbidity and mortality. Severe carotid artery stenosis (sCAS) is a well-established risk factor for such periprocedural cerebral events (ischemic or embolic) with similar risk factors to coronary artery disease. ${ }^{1}$ Measures to reduce the morbidity of perioperative stroke in patients with synchronous sCAS at the time of CABG have improved over time. ${ }^{2}$ As such, a reevaluation of the prevalence and impact of sCAS at the time of $\mathrm{CABG}$ within contemporary surgical practice is warranted.

In this issue of The Journal, Hess and colleagues ${ }^{3}$ present a retrospective analysis of 5475 patients who underwent isolated CABG within a multihospital health care system from 2011 through 2018. The authors compared 2 groups of patients who underwent CABG: 459 (8.4\%) with concurrent sCAS and $5016(91.6 \%)$ without sCAS. Perioperative and 5-year stroke rates were analyzed. Patients with sCAS in at least 1 carotid artery experienced a 3 -fold increased risk of perioperative stroke following CABG. Interestingly, less than one-half of strokes (40\%) with the sCAS group were identified on imaging to occur in locations that may have been influenced by the carotid lesion. Moreover, a history of cerebral vascular accident (CVA) correlated with a significantly greater incidence of

\footnotetext{
From the Department of Cardiovascular Surgery, Mayo Clinic, Rochester, Minn Disclosures: The authors reported no conflicts of interest.

The Journal policy requires editors and reviewers to disclose conflicts of interest and to decline handling or reviewing manuscripts for which they may have a conflict of interest. The editors and reviewers of this article have no conflicts of interest.

Received for publication July 19, 2021; revisions received July 19, 2021; accepted for publication July 19, 2021; available ahead of print Aug 12, 2021.

Address for reprints: Phillip G. Rowse, MD, Department of Cardiovascular Surgery,

Mayo Clinic, 200 First St Southwest, Rochester, MN 55905 (E-mail: rowse.

phillip@mayo.edu).

JTCVS Open 2021;7:191-2

2666-2736

Copyright (c) 2021 The Author(s). Published by Elsevier Inc. on behalf of The American Association for Thoracic Surgery. This is an open access article under the CC BY-NC-ND license (http://creativecommons.org/licenses/by-nc-nd/4.0/).

https://doi.org/10.1016/j.xjon.2021.07.018
}

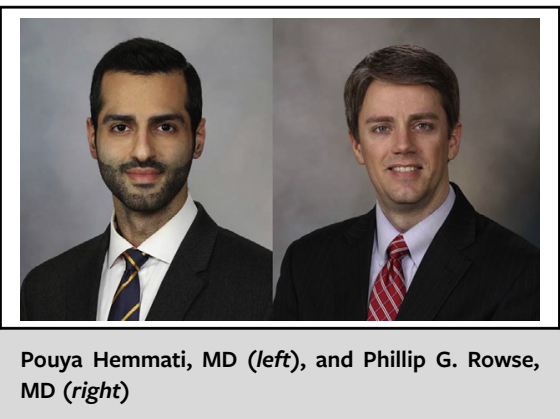

CENTRAL MESSAGE

Severe carotid stenosis remains a

predictor of postoperative

stroke following isolated coro-

nary revascularization.

perioperative stroke in both cohorts. Survival at 1 and 5 years were significantly lower in patients with sCAS. However, long-term stroke disability among survivors was not worse among patients with sCAS than in those without sCAS.

This contemporary study corroborates previously reported findings with 2 important highlights. First, a previous history of CVA and/or the presence of sCAS at the time of isolated CABG are strong predictors of perioperative stroke and mortality following isolated CABG. Second, preoperatively identified sCAS does not appear responsible for the majority of perioperative stroke. Thus, the authors conclude that ultrasonographic sCAS screening among patients undergoing isolated CABG should be selective and is best reserved for those with greater-risk features (ie, previous CVA). Furthermore, their study suggests that preoperative discovery of asymptomatic sCAS is an epiphenomenon that may serve as useful risk stratification tool during the preoperative visit but is unlikely to change surgical outcomes in the majority of patients.

While the study findings are limited by its retrospective design, it remains unclear whether pre-CABG carotid intervention may mitigate the increased risk of stroke and mortality discovered in patients with synchronous disease. A randomized controlled trial will likely be required to address this question.

\section{References}

1. Santarpino G, Nicolini F, De Feo M, Dalén M, Fischlein T, Perrotti A, et al. Prog nostic impact of asymptomatic carotid artery stenosis in patients undergoing coronary artery bypass grafting. Eur J Vasc Endovasc Surg. 2018;56:741-8. 
2. Weimar C, Bilbilis K, Rekowski J, Holst T, Beyersdorf F, Breuer M, et al; CABACS Trial Investigators. Safety of simultaneous coronary artery bypass grafting and carotid endarterectomy versus isolated coronary artery bypass grafting: a randomized clinical trial. Stroke. 2017;48:2769-75.
3. Hess NR, Killic A, Serna-Gallegos DR, Navid F, Wang Y, Thoma F, et al. Effect of untreated carotid artery stenosis at the time of isolated coronary artery bypass grafting. J Thorac Cardiovasc Surg Open. 2021;7:182-90. 